\title{
Generation of Beta Cells from Human Pluripotent Stem Cells: Potential for Regenerative Medicine
}

\author{
Maria Cristina Nostro and Gordon Keller \\ McEwen Centre for Regenerative Medicine, University Health Network, Toronto, Ontario M5G \\ 1L7, Canada
}

\section{Abstract}

The loss of beta cells in Type I Diabetes ultimately leads to insulin dependence and major complications that are difficult to manage by insulin injections. Given the complications associated with long-term administration of insulin, cell-replacement therapy is now under consideration as an alternative treatment that may someday provide a cure for this disease. Over the past 10 years, islet transplantation trials have demonstrated that it is possible to replenish beta cell function in Type I Diabetes patients and, at least temporarily, eliminate their dependency on insulin. While not yet optimal, the success of these trials has provided proof-of-principle that cell replacement therapy is a viable option for treating diabetes. Limited access to donor islets has launched a search for alternative source of beta cells for cell therapy purposes and focused the efforts of many investigators on the challenge of deriving such cells from human embryonic and induced pluripotent stem cells. Over the past five years, significant advances have been made in understanding the signaling pathways that control lineage development from hPSCs and as a consequence, it is now possible to routinely generate human insulin producing cells from both hESCs and hiPSCs. While these achievements are impressive, significant challenges do still exist, as the majority of insulin producing cells generated under these conditions are polyhormonal and non functional, likely reflecting the emergence of the polyhormonal population that is known to arise in the early embryo during the phase of pancreatic development known as the 'first transition'. Functional beta cells, which arise during the second phase or transition of pancreatic development have been generated from hPSCs, however they are detected only following transplantation of progenitor stage cells into immunocompromised mice. With this success, our challenge now is to define the pathways that control the development and maturation of this second transition population from hPSCs, and establish conditions for the generation of functional beta cells in vitro.

\section{Introduction}

Diabetes Mellitus represents a heterogeneous group of disorders characterized by hyperglycemia resulting from deficiencies in insulin production and/or insulin

Copyright (C 2012 Published by Elsevier Ltd. All rights reserved.

Publisher's Disclaimer: This is a PDF file of an unedited manuscript that has been accepted for publication. As a service to our customers we are providing this early version of the manuscript. The manuscript will undergo copyediting, typesetting, and review of the resulting proof before it is published in its final citable form. Please note that during the production process errors may be discovered which could affect the content, and all legal disclaimers that apply to the journal pertain. 
responsiveness. Two major types of diabetes exist. The first, known as juvenile or Type I diabetes is most commonly diagnosed in children or young adults and accounts for 10-20\% of reported cases of the disease. Type I diabetes results from autoimmune destruction of the beta cells, an event that is thought to be genetically and/or environmentally triggered. Type II diabetes is the more prevalent form of the disease (80-90\% of cases) and is typically diagnosed in adult life. Type II diabetes is characterized by a deficiency in insulin secretion, followed by the lack of proper response to insulin by peripheral tissues, resulting in a condition known as insulin resistance.

While Type II diabetes can be managed by combinations of drugs, weight control, diet and exercise [1], insulin administration remains the only treatment for Type I patients. Despite dramatic improvements in insulin administration, precise regulation of blood glucose levels is very difficult to achieve with exogenous insulin, resulting in states of hypo- or hyperglycemia in the patient. Dysregulation of blood glucose, in particular hyperglycemia, over the long-term can lead to severe complications in organ function, resulting in conditions such as retinopathy, nephropathy and neuropathy.

Transplantation of the entire pancreas or isolated islets has been shown to restore physiologically regulated insulin secretion in patients with Type I diabetes, demonstrating that replacement of functional beta cells may provide an effective treatment for this form of the disease. Although pancreas transplantation requires major surgery, it is effective as patients remain insulin-independent for more than 10 years [2]. Islet transplantation, on the other hand, is a relatively simple procedure and involves injection of donor-derived islets into the portal vein of patients. With the establishment of the "Edmonton protocol" in 2000, islet transplantation has improved substantially [3]. The success of this protocol is based on transplantation of an average of one million donor-derived islets per patient using a steroidfree immunosuppressive regimen. However, in contrast to whole pancreas transplantation, the function of the islet grafts appears to decline over a period of five years [4, 5]. This decline in function could be related to a suboptimal site of transplantation, the immunosuppressive regimen and/or the method of islet isolation.

A major obstacle in optimizing and expanding islet transplantation therapy for the treatment of Type I diabetes is the limited availability of donor islets. Current strategies for increasing the supply of donor material for transplantation include the use of islets from other species including the pig (xenografts) and the generation of human beta cells in vitro.

Xenotransplantation is controversial and not allowed in many countries due to the potential risk of transfer of disease across species. Despite this controversy, a clinical trial, endorsed by JDRF, is ongoing in New Zealand, where patients with Type I diabetes are transplanted with encapsulated porcine islets (DIABECELL). The trial will be completed by 2013 and its outcome could provide new information on issues relating to islet supplies and the requirement for immunosuppression and lead to a novel transplantation approaches to treat Type I diabetes (ClinicalTrials.gov Identifier: NCT00940173).

While xenografting does overcome limitations of islet supply, transplantation of humanderived cells is clearly more desirable, as it significantly reduces the risk of unknown pathogens and eliminates any issues related to differences in beta cell function between 
species. Generation of beta cells in vitro could be achieved through the following approaches: (1) differentiation of human pluripotent stem cells (hPSCs), including both embryonic (hESCs) and induced pluripotent stem cells (hiPSCs); (2) transdifferentiation of other types of cells, such as hepatic cells, acinar or alpha cells; (3) differentiation of pancreatic progenitor cells and (4) expansion of existing beta cells.

Currently, the generation of beta cells from hPSCs holds the most promise, as significant progress has been made in directing the differentiation of both hESCs and hiPSCs to a pancreatic fate. Moreover, in addition to providing a potential unlimited supply of cells for transplantation therapy, the ability to generate functional beta cells from hPSCs would establish a platform for modeling disease in vitro and for screening drugs and molecules that could impact proliferation and/or function of the insulin-producing target cell population.

In this report, we reviewed recent progress on the generation of beta cells from hPSCs and refer the reader to other excellent reviews discussing alternative ways to derive beta cells in vitro[6-10].

\section{Directed Differentiation of hPSCs to the pancreatic lineage}

Studies over the past decade have clearly demonstrated that the most efficient and reproducible method to generate a given lineage or cell type from hPSCs is to recapitulate embryonic development in the petri dish (Murry and Keller, 2008). To achieve this, stem cell biologists have translated findings from studies on model organisms including xenopus, zebrafish, chick and mouse to the hPSC model. This approach has been very successful and revealed that many of the signaling pathways that play a role during organogenesis in lower organisms are conserved in the human, allowing for the first time the study of human development in vitro.

\subsection{Induction and specification of endoderm in the embryo: a blueprint for hPSC differentiation}

In the mouse, the pancreas develops from definitive endoderm, which is generated during gastrulation in response to Wnt and high concentration of Nodal signaling (reviewed in McCracken and Wells, this issue). Once induced, the endoderm epithelium closes to form a tube that consists of three regions: foregut, midgut and hindgut. The foregut can be divided into anterior foregut, which gives rise to the thymus, thyroid, parathyroid and lung, and the posterior foregut, that generates the liver, stomach and ventral pancreas. The junction between posterior foregut and midgut is the region that gives rise to the dorsal pancreas. Midgut and hindgut will form small intestine and large intestine, respectively [11].

The earliest indication of pancreatic development is the upregulation of expression of the homeobox gene $P d x 1$ at E8.5 in the region of the gut tube fated to form the pancreas and duodenum. Shortly following the onset of PDX1 expression, distinct buds form on the endodermal epithelium, demarcating the site of pancreatic development [12-14].

The mature pancreas consists of exocrine and endocrine components. The exocrine pancreas is composed of acinar and ductal cells that secrete and transport enzymes into the intestine 
(reviewed in Cleveland, Sawyer...Leach, this issue). The endocrine pancreas is made up of islets of Langerhans that that consist of alpha $\left(\right.$ glucagon $\left.^{+}\right)$, beta $\left(\right.$insulin $\left.^{+}\right)$, delta $\left(\right.$ somatostatin $^{+}$) and PP (pancreatic polypeptide ${ }^{+}$) cells that release hormones into the bloodstream to maintain proper glucose homeostasis. Both the exocrine and endocrine pancreatic cells arise from a common progenitor in the pancreatic epithelium [15-18]. This pancreatic progenitor has been characterized by the co-expression of four transcription factors: pdx1, ptf1a, sox9 and nkx6.1 [16, 17, 19-21]. Ptf1a expression is subsequently restricted to the exocrine lineage, whereas pdx1 and nkx6.1 are expressed throughout beta cell development and maturation [12] and (reviewed in Rieck, Bankaitis and Wright, this issue).

The first hormone-producing cells are detected by E9.5 in the mouse and are predominantly glucagon-expressing cells. A subpopulation of these glucagon positive cells is polyhormonal and co-express insulin $[12,24]$. As glucose homeostasis is under maternal control at this stage, the function of these embryonic hormone positive cells is unclear. Originally, it was hypothesized that the poly-hormonal cells could represent progenitors of the adult beta cells [24]. This interpretation was, however, refuted by lineage tracing studies that showed that glucagon-expressing cells do not give rise to the adult functional beta cells $[25,26]$. These findings have led to the notion that there are two phases of pancreatic development, the first transition, leading to the generation of polyhormonal cells and the second transition, giving rise to functional endocrine cells, including beta cells (reviewed in Rieck, Bankaitis and Wright, this issue). Support for the concept of two transitions of hormonal cells has come from gene targeting studies that showed that $n k x 6.1$ null mice contain the early developing polyhormonal, but lack functional beta cells. These findings also highlighted the absolute requirement of nkx6.1 for the generation of adult beta cells during the second transition [27]. The signaling pathways regulating the development of the first and second transitions are currently not known

Taken together, the findings from these studies provide a multistage model of beta cell development that involves the induction of definitive endoderm, patterning this endoderm to a pancreatic-competent epithelium, induction of PDX-1 progenitors and generation of the first and second transition-derived endocrine lineages (Fig. 1).

\subsection{Differentiation of hPSCs: successes and challenges}

Based on this developmental scheme, the initial steps of pancreatic development from hPSCs should involve a loss of pluripotency, the formation of definitive endoderm, the development of the equivalent of the primitive gut tube and the specification of pancreatic endothelium. Under optimal conditions, these developmental steps should proceed at the expense of the other germ layers (mesoderm and ectoderm), and of the other endoderm lineages. Further differentiation along the pancreatic pathway will involve specification of the first and second transition populations and ultimately the development and maturation of the beta cell lineage. By manipulating appropriate signaling pathways in a step wise fashion, D Amour and colleagues were able to recapitulate many aspects of this developmental program in hESC differentiation cultures and in doing so generated the first pluripotent stem cell-derived human pancreatic hormone-producing cells in vitro [28]. Analyses of the insulin 
expressing cells produced in these cultures revealed that they were polyhormonal and nonfunctional, suggesting that the conditions had promoted the development of human cells equivalent of the first transition population. In a subsequent study, this group went on to demonstrate that functional beta cells could be generated in vivo in immunocompromised mice, following the transplantation of progenitor stage cells [29]. The interpretation of these findings is that progenitors of the second transition were also generated in the hESC differentiation cultures, but that the culture conditions used did not support their maturation to functional beta cells in vitro.

The protocol developed by D Amour and colleagues has been reproduced and modified by others to more accurately reflect the regulation of pancreatic development. Using a variety of modifications, different groups have reported on the generation of pancreatic lineage cells from a range of different hESC and hiPSC lines [30-41]. Collectively, the findings from these studies have provided the following insights into pancreatic development from hPSCs. First, the majority of the insulin producing cells that develop in the differentiation cultures is polyhormonal, regardless of the protocol or the hPSC line used. Second, functional monohormonal beta cells do not mature in vitro under any conditions reported to date. Third, cell lines vary in their ability to generate insulin-positive cells with a given protocol. This variability is caused in part, by different levels of expression of endogenous factors, such as BMP-4 that can influence the efficiency of pancreatic development. Fourth, stage specific inhibition of pathways is as important as activation of pathways for the directed differentiation of hPSCs to a pancreatic fate. Fifth, the pathways that regulate the development of the second transition population, defined by the emergence of $\mathrm{PDX}-1^{+} \mathrm{NKX} 6.1^{+} \mathrm{SOX} 9^{+} \mathrm{PTF} 1 \mathrm{a}^{+}$progenitors and the development of monohormonal insulin-positive cells are poorly understood.

Given that functional beta cells develop from $\mathrm{PDX}-1^{+} \mathrm{NKX} 6.1^{+} \mathrm{SOX} 9^{+} \mathrm{PTF} 1 \mathrm{a}^{+}$progenitors, the challenge that we now face is to define and characterize the regulatory networks that control their development in the differentiation cultures. With this information, it will be possible to design protocols that promote the specific and efficient differentiation of this progenitor population from different hPSCs. Access to PDX $-1^{+} \mathrm{NKX} 6.1^{+} \mathrm{SOX} 9^{+} \mathrm{PTF} 1 \mathrm{a}^{+}$ progenitors will enable detailed analyses of the pathways that promote their differentiation to a beta cell fate. As specification of this population may occur early in development, it may be necessary to revisit the strategies used for endoderm induction and patterning, as well as those for pancreatic specification to establish optimal conditions.

In this review, we will summarize approaches used to date for the directed differentiation of hPSCs to the pancreatic lineage, highlighting future directions for the generation of functional beta cells. We will focus on the following four specific developmental stages: 1) definitive endoderm formation, 2) endoderm patterning, 3) pancreatic epithelium specification and finally 4) endocrine commitment.

2.2.1 Definitive Endoderm Formation-As efficient endoderm induction is essential for optimal pancreatic development in hPSC differentiation cultures, it is important to accurately recapitulate this aspect of embryonic development in vitro. Studies with mouse ESCs were the first to demonstrate that the pathways that regulate primitive streak (PS) 
formation and endoderm induction in vivo, namely Wnt and Nodal, were also required for the generation of these populations in the differentiation cultures (Gadue et al., 2006, Kubo, 2004). Using mouse reporter ESCs, it was shown that the combination of Wnt and high concentrations of Activin A (a Nodal surrogate) were required to promote the development of the equivalent of the anterior primitive streak (APS) population. Additional Activin A/ Nodal signaling led to the induction of definitive endoderm from the APS. The requirement for these pathways is conserved in the human, as activation of both is required for PS and definitive endoderm development in hPSC cultures \{D'Amour, $2006 \# 1052\}$. A recent report by $\mathrm{Xu}$ and colleagues suggests that additional factors may be required for optimal endoderm induction and provided evidence that the combination of Activin A, BMP4 and FGF2 induces endoderm more efficiently from hESCs than Activin A alone or the combinations of Activin A/FGF2 and Activin A/BMP4 [40]. Although Wnt was not used in this study, it is likely that endogenous levels of WNT signaling were sufficient to promote PS and definitive endoderm formation as shown in previous studies [42, 43]. This study also demonstrated that the addition of insulin to the culture media favored mesodermal development through stimulation of the PI3K pathway. This observation supports earlier studies demonstrating that inhibition of the PI3K pathway, with either LY294002 or wortmannin in combination with Activin A, was more efficient at inducing endoderm compared to Activin A alone [41, 44]. Taken together, these findings highlight the importance of defining the signaling pathways that control the earliest stages of pancreatic development and indicate that components such as insulin, found in most commercial serum-free media, can dramatically influence the efficiency of differentiation.

2.2.1.1 Definitive Endoderm Markers: To ensure efficient and reproducible differentiation, it is essential to identify markers that allow one to monitor endoderm development. While expression of genes such as FOXA2 and SOX17 is used to demonstrate the presence of definitive endoderm, flow cytometric analyses of surface markers allows for rapid quantitative assessment of the efficiency and kinetics of differentiation. This approach, however, is dependent on the availability of high quality antibodies to markers that are preferentially found on the endoderm lineage. One such marker, the chemokine receptor CXCR4, was identified by microarray analysis to be specifically up-regulated in mouse definitive, but not visceral, endoderm [42, 45, 46]. A recent study, using a SOX17-GFP reporter hESC line confirmed that CXCR4 is expressed on SOX17 $7^{+}$definitive endoderm [47]. Other surface markers found on endoderm include EPCAM (Sherwood et al., 2007) and the receptor tyrosine kinase c-KIT (Gouon-Evans et al., 2006). Given that none of these markers is endoderm specific, combinations of antibodies are required to monitor the efficiency of endoderm induction and to identify contaminating lineages within the culture. For instance, co-staining with CXCR4 and EPCAM can be used to quantify the proportion of endoderm $\left(\mathrm{CXCR} 4^{+} / \mathrm{EPCAM}^{+}\right)$and undifferentiated ES cells $\left(\mathrm{CXCR} 4^{-} / \mathrm{EPCAM}^{+}\right)$ whereas the combination of PDGFRa and/or KDR allows one to monitor mesoderm contamination [38, 48-50]. While these antibody combinations are routinely used, the identification or generation of an endoderm specific antibody would be important, as it would provide an easy single step method for monitoring induction of this germ layer and a method for isolating large quantities of pure endoderm through cell sorting. Purification at 
the definitive endoderm step may be important for clinical translation, as it would provide an enriched cell product free of contaminating PSCs, mesoderm and ectoderm.

2.2.1.2 Definitive Endoderm Yield: Most studies using hPSC lines report that between $52 \%$ and $95 \% \mathrm{CXCR}^{+}$cells can be generated in vitro following 3 days to 5 days of differentiation either in a monolayer or embryoid body (EB) format [28, 31, 38, 41]. Although efficiency of differentiation can be very high, the total cell yield is often very poor. In some cases a four-fold increase from undifferentiated hPSC to d5-endoderm has been reported [44], but in the majority of cases we are faced with a loss of cells during the differentiation of pluripotent cells to definitive endoderm [51]. Several efforts are underway to generate bioreactor platforms that would allow expansion of the endoderm population, so that we will be able to scale-up this process for the future use of endoderm-derived cells in clinical studies and/or for drug testing. In a recent study, Ungrin and colleagues identified a novel approach to generate higher yield of definitive endoderm from hPSCs by optimizing the formation of size-specific aggregates at the start of the differentiation. The aggregates are generated in the presence of ROCK inhibitor, maintained in individual wells and allowed to differentiate under serum-free conditions in the presence of Activin A, bFGF, VEGF and low levels of BMP. By using this approach, the authors were able to achieve a 23 -fold expansion over five days of differentiation using the HES2 cell line and an average of 5-fold expansion using H9, H1 and 38-2 IPS lines. This approach is scalable and should allow the generation of cells in therapeutically useful quantities [51].

\subsubsection{Patterning definitive endoderm in hPSC cultures}

2.2.2.1 Manipulating Nodal signaling: In addition to its pivotal role in primitive streak formation and endoderm induction, Nodal signaling is also involved in antero-posterior patterning of the gut tube. Findings from studies on mice carrying a Nodal hypomorphic allele suggest that high levels of signaling are required for the formation of the foregut endoderm, whereas lower levels promote the development of hindgut endoderm and mesoderm [52]. Similarly, using mouse and human PSCs, it has been shown that low levels of Activin A will induce mesodermal cells, while higher concentrations generate anterior primitive streak-derivatives. Whether or not low levels of Activin A are also adequate to induce intestinal derivatives has not been established in vitro using the hPSC model.

Together with levels of signaling, the timing of TGF- $\beta$ signaling also appears to play a role in patterning definitive endoderm [53]. Evidence in support of this is the observation that the precursors of Anterior Definitive Endoderm (ADE) upregulate expression of the TGF- $\beta$ inhibitors Lefty 1 and Cerberus-like immediately after their induction, suggesting that Nodal signaling is only required for a narrow period of time to induce anterior foregut endoderm [54]. By translating this information to hESC differentiation cultures, Green et al. demonstrated that it is possible to induce an anterior foregut fate by inhibiting TGF- $\beta$ signaling immediately following endoderm induction [48]. On the other hand, sustained TGF- $\beta$ signaling, following definitive endoderm induction, promotes posterior foregut and hepatic development (Ogawa manuscript in preparation, [55]). A restricted period of Activin A signaling followed by activation of the WNT and FGF (FGF4) signaling pathways induces a posterior phenotype allowing intestinal differentiation [55] (Fig. 2). 
Studies on pancreatic development have shown that the duration of Nodal (Activin A) signaling dramatically impacts the level of endocrine cell development and that this effect is influenced by the culture format used for differentiation [38]. CXCR $4^{+} \mathrm{c}-\mathrm{KIT}^{+}$endoderm generated through five days of EB differentiation requires additional Activin A/Nodal signaling for optimal pancreatic development, as measured by the production of insulinproducing cells. The duration of signaling is, however, critical as endoderm treated for 72 hours gave rise to significantly fewer insulin-producing cells than that treated for 48 hours. If, on the other hand, the endoderm is induced in a monolayer format ( 3 days of differentiation), additional Activin A signaling is not required for pancreatic commitment. Indeed, prolonged signaling under these conditions significantly decreases pancreatic development. These observations clearly indicate that optimal levels of Activin A/Nodal signaling are required for patterning the hESC-derived definitive endoderm to a "pancreaticcompetent" fate. This timing is, however, influenced by the method used for induction of the definitive endoderm and possibly by the hESC line used. Given this variability, the identification of cell surface and/or molecular markers to further define this "pancreaticcompetent" stage would represent an important step forward, as it would allow for rapid optimization of pancreatic development from different hPSC lines.

These findings reinforce the concept that endoderm induced at different times will display different potential, similar to temporal differences associated with mesoderm induction [56, 57]. By monitoring the kinetics of endoderm induction in detail, it should be possible to identify subpopulations that display enhanced pancreatic potential and reduced potential to generate other derivatives. Future experiments will be required to better define how temporal aspects of endoderm development impact derivation of endodermal lineages from hPSC cultures.

2.2.2.2 FGF and WNT signaling: Both FGF and WNT have been shown to play a role in patterning the gut tube in vivo (reviewed in McCracken and Wells, this issue), as well as in hPSC differentiation cultures [30, 38, 55, 58, 59]. FGF7 and FGF10 are expressed in human embryonic pancreatic mesenchyme and can induce proliferation of human pancreatic explants [60]. In the mouse embryo, fgf10 has been shown to play a role in promoting the proliferation of pancreatic progenitors most likely through notch activation [61-65]. In hPSC differentiation cultures, members of the FGF family, in particular FGF7/KGF and FGF10 are routinely added to the cultures prior to PDX1 induction to pattern the definitive endoderm to the equivalent region of the primitive gut tube that is competent to form the pancreatic epithelium $[28,29,38,39]$. The importance of this patterning step has been recently reinforced by the studies of Kelly and colleagues [66] that showed that $\mathrm{PDX1}^{+} /$ NKX6.1 $1^{+}$second transition progenitors do not develop if FGF7 is omitted from the culture. A requirement for FGF signaling during endoderm patterning, has also been demonstrated by studies showing that the addition of inhibitors of this pathway, including SU5402, LY294002 and U1026, will block the formation of PDX1 progenitors [30, 36]. The role for FGF signaling in pancreatic development extends beyond the patterning step, as the addition of FGF4 to hPSC differentiation cultures during the retinoic acid (RA) mediated PDX1 induction step increases PDX1 expression, likely through enhancement of progenitor cell survival [34]. These observations suggest that FGF10 and/or FGF7 act at two different 
stages: prior to $P D X 1$ induction to pattern the primitive gut and following $P D X 1$ induction to stimulate proliferation of the pancreatic progenitors.

While the requirement for FGF7 or FGF10 for patterning hPSC-derived endoderm is well established, the underlying molecular mechanisms involved in the generation of pancreatic competent endoderm are not well understood. One change that is associated with this transition is a reduction in the levels of the transcription factor SOX17. Although sox 17 is broadly expressed in the primitive gut tube in the mouse embryo, as patterning proceeds it is not expressed in the dorsal pancreatic bud and its expression is downregulated immediately after the onset of $p d x l$ expression in the ventral pancreatic bud [67]. These findings suggest that sox 17 expression must be downregulated to allow pancreatic development to take place. This interpretation is supported by gain-of-function studies showing that enforced expression of sox 17 from the $p d x 1$ promoter impairs pancreatic development [67]. In hPSC cultures, a decrease in SOX17 expression is observed following the addition of FGF10 to the endoderm population, suggesting that this signaling pathway may play a role in the regulation of expression of this transcription factor [28, 38]. Future gain- and loss-offunction experiments will be required to formally document this regulatory pathway.

Canonical Wnt signaling has been shown to play a role during endoderm patterning in xenopus embryo, where it functions to establish a posterior phenotype [59] (reviewed in McCracken and Wells, this issue). A similar posteriorizing role for this pathway has been shown in hPSC cultures. Activation of the pathway in hESC-derived endoderm promotes a posterior fate as demonstrated by the upregulation of expression of the posterior marker $C D X 2$ and the subsequent generation of intestinal lineage cells [38, 55]. Inhibition of WNT signaling, on the other hand, significantly reduced $C D X 2$ expression. In addition to its role in establishing an anterior-posterior gut tube axis, low levels of Wnt signaling also appear to be required for the generation of insulin-expressing cells, indicating that this pathway, like many others, plays a role at multiple stages of development [38] (reviewed in Serup, this issue).

2.2.2.3 BMP signaling: Recent studies indicate that Bmp signaling is not active in the dorsal pancreatic bud, prior to or after $p d x l$ induction, suggesting that it is not required for establishment of this lineage [68]. Findings from hPSC differentiation studies are consistent with these observations as BMP is not included in many of the induction protocols. In fact, most observations indicate that BMP is inhibitory to pancreatic development, as the pathway needs to be blocked at multiple stages to promote PDX1 induction and endocrine development $[31,32,36,38]$. We recently demonstrated that inhibition of the pathway during the patterning step was required for some, but not all of the hPSC lines tested (Table 1). Without addition of BMP inhibitors at this step, differentiation proceeded along a hepatic rather than a pancreatic fate. Inhibition at later stages, during the PDX1 induction and endocrine specification steps was required for all cell lines tested. These observations indicate that hPSC-derived endoderm produces BMPs and that the levels of endogenous factor vary between cell lines. High levels of endogenous BMP at the patterning step promote hepatic rather than pancreatic development, consistent with the well described role of this pathway in hepatic development [69]. Different levels of endogenous BMP signaling may be one factor that contributes to the well-established heterogeneity in differentiation 
potential of different hPSCs [70-73] and a likely explanation for the difficulty in achieving efficient differentiation with different cell lines with a single protocol.

2.2.3 Specification of the pancreatic epithelium-The earliest stage of pancreatic development is marked by the emergence of distinct buds comprised of PDX1 positive progenitors at two independent regions of the gut tube; the ventral foregut and the foregut to midgut junction [11]. While progeny from both regions contribute to pancreatic development, they are patterned through different regulatory pathways. The generation of $\mathrm{pdx} 1$ expressing cells in the murine dorsal pancreas requires the presence of RA and the inhibition of bmp and shh signaling [68, 74-78]. Low BMP signaling originating from the septum transversum is, however, likely to play a role during PDX1 induction in the ventral foregut [68]. These differences could be one explanation as to why different groups have been able to generate hPSC-derived PDX1-expressing cells using combinations of a variety of cytokines and small molecules, including FGF2, FGF7, FGF10, FGF4, EGF, NOGGIN or Dorsomorphin, RA, Cyclopamine and SB431541 (Table 2). As there are few markers that distinguish dorsal and ventral pancreas, it is difficult to determine which is induced under a given set of conditions in the hPSC cultures. Most protocols likely promote the development of the dorsal population as RA is used to induce PDX1 in the hPSC-derived endoderm [31, 34], while BMP inhibitors are added to block hepatic development [31, 36, 38]. Depending on the protocol, RA is added either following [28, 29, 37-39] or during a patterning step $[31,34-36,41]$ and is maintained in the cultures for anywhere between 2 and 8 days (Table 2). While all permutations result in the generation of $\mathrm{PDX} 1^{+}$progenitors, it is not known if these progenitors display similar capacity to differentiate to endocrine lineage cells. In some studies induction of PDX1 has been reported in absence of the addition of RA and BMP inhibitors [30, 40]. Under these conditions, a source of RA (retinol) may be provided as a component of the media and the cells may express very low levels of endogenous BMP or the equivalent of a ventral pancreas is generated.

In addition to activation of the RA pathway, inhibition of Shh in the region of the primitive gut tube that gives rise to the pancreas is essential for pancreatic specification during mouse development. This has been best demonstrated by studies showing that enforced expression of Shh from the $p d x 1$ promoter inhibits the development of the pancreas [78, 79]. Based on these studies, the SHH inhibitor cyclopamine is routinely added to the differentiation cultures during the RA induction step. Although most protocols do include a SHH inhibitor, the levels of endogenous SHH signaling and the requirement for inhibition of this pathway has not been formally tested in the hPSC differentiation cultures. Other regulatory pathways may also play a role at this step as the addition of Indolactam $\mathrm{V}$, a potent activator of protein kinase $\mathrm{C}$ (PKC), has also been used to improve PDX1, NGN3, NKX2.2 and NKX6.1 expression following RA treatment [80-82]. Given the importance of endothelial and mesenchymal cells during PDX1 progenitors formation and expansion [83], future experiments should investigate the effect of co-culturing hPSC-derived primitive gut tube with endothelial and mesenchymal cells, in order to clarify whether cellular interactions could impact the generation and proliferation of the pancreatic epithelium in vitro. 


\subsection{Endocrine Lineage commitment}

The pathways regulating the commitment and maturation of the endocrine lineages from the PDX1 progenitors are not completely understood, and as a consequence the efficiency of generating insulin-producing cells varies widely between labs. Studies on the early mouse embryo have shown that Notch signaling does play an important role at this stage, as activation of the pathway blocks transcriptional activity of the $n g n 3$ promoter, and as a consequence, inhibits differentiation towards the endocrine lineage [84] (reviewed in Serup, this issue). Targeting of different components of the Notch pathway including hes1, delta like ligand 1 (dll1) and rbp- $\mathrm{j}_{\mathrm{k}}$ in knock-out mice results in the up-regulation of $n g n 3$ and endocrine differentiation, supporting the interpretation that activation of the pathway arrests differentiation at the progenitor stage $[61,64,85]$. Given these observations, Notch inhibitors (DAPT, Compound E or L-685,458) are often included in the hPSC differentiation cultures following the induction of the PDX1 progenitor population. However, even under these conditions, differentiation to insulin expressing cells is inefficient and variable between different hPSC lines.

Based on the observations in the mouse embryo that pancreatic development proceeds normally in the absence of smad4 (BMP and TGF- $\beta$ ) signaling following PDX1 induction [86], we examined the effect of inhibiting BMP and TGF- $\beta$ /Activin A/Nodal at this stage in the differentiation cultures. Inhibition of both pathways led to a 60 -fold increase in the levels of insulin expression and 3.5 fold increase in the total number of cells [38]. Analyses of each pathway independently revealed that inhibition of BMP signaling was primarily responsible for the increase in insulin expression, whereas inhibition of TGF- $\beta /$ Activin A/Nodal led to an increase in cell numbers, likely promoting the survival and expansion of the newly formed endocrine cells. Inhibition of these pathways was required for efficient endocrine development from all cell lines tested. Using a screening approach, Rezania and colleagues also found that inhibition of TGF- $\beta$ was important at this stage and identified the inhibitor ALK5 kinase inhibitor II as a factor that improves the efficiency of endocrine cell development from $\mathrm{PDXI}^{+}$progenitors [39]. However, given that all of their studies were carried out in the presence of the BMP inhibitor Noggin, they were unable to segregate the effect of inhibiting BMP from that of inhibiting TGF- $\beta$ /Activin A/Nodal. Kunisada and colleagues also used a screening approach to identify molecules that could enhance the generation of insulin expressing cells from $P D X 1$ progenitors [35]. From this screen, they identified forskolin (an adenylate cyclase activator), dexamethasone and the ALK5 inhibitor II as compounds that could increase the levels of insulin expression. The fact that differentiation in their hands progressed to the stage of insulin expression in the absence of BMP inhibition suggest that the iPSC lines they used do not produce high levels of endogenous BMP and/or that the conditions (media) used do not induce endogenous expression. Similarly, it is possible that the Cythera lines, particularly Cyt203, used for the pancreatic differentiation studies reported by D Amour and colleagues [28] have very low levels of endogenous BMP and Activin A/Nodal/TGF- $\beta$ activity and, as a consequence, generate insulin positive cells without the requirement for inhibitors of these pathways.

Taken together, the findings from these studies have moved us one step closer to elucidating the regulatory pathways that regulate the specification and maturation of the endocrine cells 
from the PDX1 progenitor population (Fig. 3). It is worth emphasizing that different strategies uncovered the same pathway inhibitors as molecules that promoted the generation of insulin positive cells. These observations highlight the importance of stage specific inhibition of pathways for the directed differentiation of hPSCs to a particular lineage.

\section{Characterization of the insulin-producing cells generated in vitro}

The majority of insulin positive cells generated by most protocols are polyhormonal, often co-expressing glucagon and insulin or glucagon, insulin and somatostatin. Very few ghrelin and pancreatic polypeptide-expressing cells are detected in the differentiation cultures.

Analyses of these cells in many different labs have failed to demonstrate insulin secretion in response to high glucose stimulation, indicating that they are unable to function as a mature beta cell. The development of a reporter hESC line in which the green fluorescent protein (GFP) cDNA is targeted to the INS locus has enabled the isolation and detailed characterization of these cells $[37,38,87]$. Molecular profiling of these isolated cells confirmed their poly-hormonal nature and revealed that they express high levels of $A R X$ an alpha cell specific transcription factor and lack expression of the beta cell transcription factor NKX6.1.

While polyhormonal cells represent the predominant cell type in the differentiation cultures, some monohormal cells are generated. Electrophysiological analysis of the INS:GFP ${ }^{+}$cell populations induced with our protocol revealed that $40-50 \%$ of the cells display beta cell characteristics including $\mathrm{K}_{\text {ATP }}$ activity, glucose-mediated $\mathrm{Ca}^{2+}$ uptake and nifedipineresistant $\mathrm{Ca}_{\mathrm{V}}$ currents. However, despite these properties, glucose responsive insulin secretion was not detected, suggesting a deficiency in glucose sensing, metabolism, insulin processing and/or exocytosis [38, 87]. Kunisada and colleagues demonstrated that the combination of the ALK5 inhibitor II, forskolin, dexamethasone and nicotinamide gave rise to a higher percentage of mono-hormonal c-peptide ${ }^{+} /$glucagon $^{-}$cells, compared to treatment with ALK5 inhibitor II alone. However, although the cells are monohormonal, they lack glucose responsiveness, indicating that the combination of forskolin, dexamethasone, nicotinamide and ALK5 inhibitor II is not sufficient to induce beta cell maturation [35].

Although the early developing population does express insulin, three different transplant studies suggest that they may in fact, represent alpha cell progenitors. When transplanted into the mammary fat pad of immunocompromised mice, we showed that the purified INS$\mathrm{GFP}^{+}$cells generated islet-like grafts that consist of glucagon positive cells that no longer expressed insulin [87]. Rezania and colleagues transplanted unfractionated differentiated populations and similarly showed the development of large grafts of alpha-like cells that were able to secrete glucagon in vivo [39]. In the third and most recent study, Kelly and colleagues demonstrated that the poly-hormonal cells expressed CD318 and that populations enriched for this marker give rise to alpha-like cells in vivo [66].

The observation that the hPSC-derived polyhormonal cells give rise to alpha cells in vivo is consistent with studies in the mouse embryo which suggest that the insulin-expressing cell population generated during the first transition might generate a small percentage of adult alpha cells [26]. Recent studies have identified a similar polyhormonal population in human 
fetal tissues $[88,89]$ further supporting the interpretation that these cells represent a normal stage of pancreatic development, possibly the first alpha cells progenitors [89].

As lineage tracing studies indicate that glucagon-expressing cells do not give rise to the mature beta cells [26], it is likely that this early developing population is unable to generate functional beta cells. However, given the observation that over-expression of the beta cell transcription factor PAX4 within the alpha cell lineage is sufficient to induce an alpha-to beta conversion [90], it may be possible to direct the differentiation of the polyhormonal cells to a beta cell fate. Support for this interpretation comes from studies showing that in conditions of complete beta cell ablation, alpha cells retain some level of plasticity and are able to transdifferentiate to beta cells through activation of a beta cell program [91, 92]. Identifying the signaling pathway that are able to instruct an alpha cell to transdifferentiate to a beta cells represents an exciting possibility for generating new beta cells in vitro and ultimately in vivo.

\section{First and second transition: implications for hPSC directed differentiation}

The consensus from most studies is that the endocrine cells generated in vitro from hPSCs likely represent the "first transition" of pancreatic development, a stage during which hormone-producing cells are generated. These early developing insulin positive cells do not contribute to the adult islets of Langherans and most likely give rise to a small percentage of adult alpha cells [26]. If human pancreatic development is similar to that of the mouse, functional beta cells will be generated during a second transition that will be defined early by the expression of the transcription factor NKX6.1. A recent study by Kelly et al. [66] has identified a putative hESC-derived second transition NKX6. $1^{+}$progenitor population, based on expression of the surface marker CD142. Isolated CD142+ cells were found to co-express NKX6.1 and PDX-1 and to give rise to functional beta cells five months following transplantation into Scid-beige mice. In addition to beta cells, the CD142+ population gave rise to other hormone-producing cells, exocrine and ductal cells, suggesting that it may contain multipotential pancreatic progenitors. CD142 is not, however, specific for the second transition progenitor population, as it is expressed on other populations that develop in cultures generated in suboptimal conditions [66]. Nevertheless, these findings represent an important step forward, as the identification of surface markers such as CD142 will ultimately enable us to easily monitor the emergence of the second transition population in PSC differentiation cultures and in doing so, define the signaling pathways that regulate the generation of these progenitors. It is worth emphasizing that the signaling pathways driving the generation of the progenitor of the second transition still eludes us. The Cythera hESC lines, CytT49 and CyT203, used by Kelly and colleagues generate $45.7 \%$ and $25.7 \%$ CD $142^{+} \mathrm{PDX} 1^{+} \mathrm{NKX} 6-1^{+}$cells, respectively. However, using the same differentiation strategy, the hESC line MEL1 only gives rise to $6.25 \% \mathrm{CD} 142^{+} \mathrm{PDX} 1{ }^{+} \mathrm{NKX} 6-1^{+}$cells. These findings highlight important and interesting differences in the propensity of hPSCs to generate second transition cells and the requirement for a reliable approach that could be broadly used to differentiate any hPSC line to pancreatic endocrine cells. To this end, the identification of additional markers that distinguish first and second transition populations is 
an important goal to enable the widespread use of flow cytometric approaches to monitor beta cell differentiation and for the isolation of defined populations for teratoma-free transplantation.

\section{Conclusions and future directions}

In the recent years our knowledge and understanding of hPSC-differentiation and lineage commitment have grown exponentially and, as a consequence, we are now able to efficiently and reproducibly generate pancreatic cell populations from different hESC and hiPSC lines. These advances are truly remarkable and have brought us an important step closer to developing novels sources of human beta cells for transplantation therapy and drug discovery. However, important challenges remain, as the pathways regulating the development of the progenitors of the second transition beta cell and their maturation to functional cells in vitro are not well understood. As with the early stages of differentiation, developmental biology will continue to inform the stem cell biologists and as a consequence, it will be important to continue to translate findings from the embryo to the hPSC cultures. Insights may also come from comparisons of cell lines, such as CyT49 and CyT203 that do generate the second transition population with current protocols to cells lines that do not. In particular, epigenetic and expression profiling of the different PSCs could provide novel information on their "pancreatic propensity" and on signaling pathways that regulate the generation and maturation of beta cell-progenitors in vitro. Once we achieve these goals, our efforts can shift to the expansion, survival and immune protection of the cells generated in vitro in order to fully realize the goal of hPSC-driven regenerative medicine.

\section{Acknowledgments}

We would like to thank Audrey Holtzinger, Andrea Ditadi and Christopher Sturgeon for their useful comments on the manuscript. Our work is supported by a grant from NIH/NIDDK (U01-DK072513) and by the McEwen Centre for Regenerative Medicine.

\section{References}

1. Knowler WC, Barrett-Connor E, Fowler SE, Hamman RF, Lachin JM, Walker EA, et al. Reduction in the incidence of type 2 diabetes with lifestyle intervention or metformin. N Engl J Med. 2002; 346:393-403. [PubMed: 11832527]

2. Meloche RM. Transplantation for the treatment of type 1 diabetes. World J Gastroenterol. 2007; 13:6347-55. [PubMed: 18081223]

3. Shapiro AM, Lakey JR, Ryan EA, Korbutt GS, Toth E, Warnock GL, et al. Islet transplantation in seven patients with type 1 diabetes mellitus using a glucocorticoid-free immunosuppressive regimen. N Engl J Med. 2000; 343:230-8. [PubMed: 10911004]

4. Ryan EA, Paty BW, Senior PA, Bigam D, Alfadhli E, Kneteman NM, et al. Five-year follow-up after clinical islet transplantation. Diabetes. 2005; 54:2060-9. [PubMed: 15983207]

5. Shapiro AM, Ricordi C, Hering BJ, Auchincloss H, Lindblad R, Robertson RP, et al. International trial of the Edmonton protocol for islet transplantation. N Engl J Med. 2006; 355:1318-30. [PubMed: 17005949]

6. Baiu D, Merriam F, Odorico J. Potential pathways to restore beta-cell mass: pluripotent stem cells, reprogramming, and endogenous regeneration. Current diabetes reports. 2011; 11:392-401. [PubMed: 21800022] 
7. Chung CH, Levine F. Adult pancreatic alpha-cells: a new source of cells for beta-cell regeneration. Rev Diabet Stud. 2010; 7:124-31. [PubMed: 21060971]

8. Collombat $\mathrm{P}, \mathrm{Xu} \mathrm{X}$, Heimberg H, Mansouri A. Pancreatic beta-cells: from generation to regeneration. Semin Cell Dev Biol. 2010; 21:838-44. [PubMed: 20688184]

9. Sumi S. Regenerative medicine for insulin deficiency: creation of pancreatic islets and bioartificial pancreas. Journal of hepato-biliary-pancreatic sciences. 2011; 18:6-12. [PubMed: 20589399]

10. Yechoor V, Chan L. Minireview: beta-cell replacement therapy for diabetes in the 21 st century: manipulation of cell fate by directed differentiation. Mol Endocrinol. 2010; 24:1501-11. [PubMed: 20219891]

11. Wells JM, Melton DA. Vertebrate endoderm development. Annu Rev Cell Dev Biol. 1999; 15:393-410. [PubMed: 10611967]

12. Jorgensen MC, Ahnfelt-Ronne J, Hald J, Madsen OD, Serup P, Hecksher-Sorensen J. An illustrated review of early pancreas development in the mouse. Endocr Rev. 2007; 28:685-705. [PubMed: 17881611]

13. Murtaugh LC. Pancreas and beta-cell development: from the actual to the possible. Development (Cambridge, England). 2007; 134:427-38.

14. Murtaugh LC, Melton DA. Genes, signals, and lineages in pancreas development. Annu Rev Cell Dev Biol. 2003; 19:71-89. [PubMed: 14570564]

15. Gu G, Brown JR, Melton DA. Direct lineage tracing reveals the ontogeny of pancreatic cell fates during mouse embryogenesis. Mechanisms of development. 2003; 120:35-43. [PubMed: 12490294]

16. Gu G, Dubauskaite J, Melton DA. Direct evidence for the pancreatic lineage: NGN3+ cells are islet progenitors and are distinct from duct progenitors. Development. 2002; 129:2447-57. [PubMed: 11973276]

17. Kawaguchi Y, Cooper B, Gannon M, Ray M, MacDonald RJ, Wright CV. The role of the transcriptional regulator Ptf1a in converting intestinal to pancreatic progenitors. Nat Genet. 2002; 32:128-34. [PubMed: 12185368]

18. Kim SK, MacDonald RJ. Signaling and transcriptional control of pancreatic organogenesis. Curr Opin Genet Dev. 2002; 12:540-7. [PubMed: 12200159]

19. Hald J, Sprinkel AE, Ray M, Serup P, Wright C, Madsen OD. Generation and characterization of Ptf1a antiserum and localization of Ptf1a in relation to Nkx6. 1 and Pdx1 during the earliest stages of mouse pancreas development. J Histochem Cytochem. 2008; 56:587-95. [PubMed: 18347078]

20. Seymour PA, Freude KK, Tran MN, Mayes EE, Jensen J, Kist R, et al. SOX9 is required for maintenance of the pancreatic progenitor cell pool. Proc Natl Acad Sci U S A. 2007; 104:1865-70. [PubMed: 17267606]

21. Zhou Q, Law AC, Rajagopal J, Anderson WJ, Gray PA, Melton DA. A multipotent progenitor domain guides pancreatic organogenesis. Dev Cell. 2007; 13:103-14. [PubMed: 17609113]

22. Gradwohl G, Dierich A, LeMeur M, Guillemot F. neurogenin3 is required for the development of the four endocrine cell lineages of the pancreas. Proceedings of the National Academy of Sciences of the United States of America. 2000; 97:1607-11. [PubMed: 10677506]

23. Schwitzgebel VM, Scheel DW, Conners JR, Kalamaras J, Lee JE, Anderson DJ, et al. Expression of neurogenin 3 reveals an islet cell precursor population in the pancreas. Development (Cambridge, England). 2000; 127:3533-42.

24. Teitelman G, Alpert S, Polak JM, Martinez A, Hanahan D. Precursor cells of mouse endocrine pancreas coexpress insulin, glucagon and the neuronal proteins tyrosine hydroxylase and neuropeptide Y, but not pancreatic polypeptide. Development. 1993; 118:1031-9. [PubMed: 7903631]

25. Herrera PL. Adult insulin- and glucagon-producing cells differentiate from two independent cell lineages. Development. 2000; 127:2317-22. [PubMed: 10804174]

26. Herrera PL, Huarte J, Zufferey R, Nichols A, Mermillod B, Philippe J, et al. Ablation of islet endocrine cells by targeted expression of hormone-promoter-driven toxigenes. Proc Natl Acad Sci U S A. 1994; 91:12999-3003. [PubMed: 7809163] 
27. Sander M, Sussel L, Conners J, Scheel D, Kalamaras J, Dela Cruz F, et al. Homeobox gene Nkx6.1 lies downstream of Nkx2. 2 in the major pathway of beta-cell formation in the pancreas. Development. 2000; 127:5533-40. [PubMed: 11076772]

28. D'Amour KA, Bang AG, Eliazer S, Kelly OG, Agulnick AD, Smart NG, et al. Production of pancreatic hormone-expressing endocrine cells from human embryonic stem cells. Nat Biotechnol. 2006; 24:1392-401. [PubMed: 17053790]

29. Kroon E, Martinson LA, Kadoya K, Bang AG, Kelly OG, Eliazer S, et al. Pancreatic endoderm derived from human embryonic stem cells generates glucose-responsive insulin-secreting cells in vivo. Nat Biotechnol. 2008; 26:443-52. [PubMed: 18288110]

30. Ameri J, Stahlberg A, Pedersen J, Johansson JK, Johannesson MM, Artner I, et al. FGF2 specifies hESC-derived definitive endoderm into foregut/midgut cell lineages in a concentration-dependent manner. Stem Cells. 2010; 28:45-56. [PubMed: 19890880]

31. Cai J, Yu C, Liu Y, Chen S, Guo Y, Yong J, et al. Generation of homogeneous PDX1(+) pancreatic progenitors from human ES cell-derived endoderm cells. Journal of molecular cell biology. 2009; 2:50-60. [PubMed: 19910415]

32. Jiang J, Au M, Lu K, Eshpeter A, Korbutt G, Fisk G, et al. Generation of insulin-producing isletlike clusters from human embryonic stem cells. Stem Cells. 2007; 25:1940-53. [PubMed: 17510217]

33. Jiang W, Shi Y, Zhao D, Chen S, Yong J, Zhang J, et al. In vitro derivation of functional insulinproducing cells from human embryonic stem cells. Cell research. 2007; 17:333-44. [PubMed: 17426693]

34. Johannesson M, Stahlberg A, Ameri J, Sand FW, Norrman K, Semb H. FGF4 and retinoic acid direct differentiation of hESCs into PDX1-expressing foregut endoderm in a time- and concentration-dependent manner. PLoS ONE. 2009; 4:e4794. [PubMed: 19277121]

35. Kunisada Y, Tsubooka-Yamazoe N, Shoji M, Hosoya M. Small molecules induce efficient differentiation into insulin-producing cells from human induced pluripotent stem cells. Stem Cell Res. 2011

36. Mfopou JK, Chen B, Mateizel I, Sermon K, Bouwens L. Noggin, Retinoids, and Fibroblast Growth Factor Regulate Hepatic or Pancreatic Fate of Human Embryonic Stem Cells. Gastroenterology. 2010

37. Micallef SJ, Li X, Schiesser JV, Hirst CE, Yu QC, Lim SM, et al. INS (GFP/w insulin-producing cells. Diabetologia. 2011

38. Nostro MC, Sarangi F, Ogawa S, Holtzinger A, Corneo B, Li X, et al. Stage-specific signaling through TGFbeta family members and WNT regulates patterning and pancreatic specification of human pluripotent stem cells. Development. 2011; 138:861-71. [PubMed: 21270052]

39. Rezania A, Riedel MJ, Wideman RD, Karanu F, Ao Z, Warnock GL, et al. Production of Functional Glucagon-Secreting Alpha Cells from Human Embryonic Stem Cells. Diabetes. 2011

40. Xu X, Browning VL, Odorico JS. Activin, BMP and FGF pathways cooperate to promote endoderm and pancreatic lineage cell differentiation from human embryonic stem cells. Mech Dev. 2011; 128:412-27. [PubMed: 21855631]

41. Zhang D, Jiang W, Liu M, Sui X, Yin X, Chen S, et al. Highly efficient differentiation of human ES cells and iPS cells into mature pancreatic insulin-producing cells. Cell research. 2009; 19:42938. [PubMed: 19255591]

42. D'Amour KA, Agulnick AD, Eliazer S, Kelly OG, Kroon E, Baetge EE. Efficient differentiation of human embryonic stem cells to definitive endoderm. Nat Biotechnol. 2005; 23:1534-41. [PubMed: 16258519]

43. Gadue P, Huber TL, Paddison PJ, Keller GM. Wnt and TGF-beta signaling are required for the induction of an in vitro model of primitive streak formation using embryonic stem cells. Proc Natl Acad Sci U S A. 2006; 103:16806-11. [PubMed: 17077151]

44. McLean AB, D’Amour KA, Jones KL, Krishnamoorthy M, Kulik MJ, Reynolds DM, et al. Activin a efficiently specifies definitive endoderm from human embryonic stem cells only when phosphatidylinositol 3-kinase signaling is suppressed. Stem Cells. 2007; 25:29-38. [PubMed: 17204604] 
45. Gouon-Evans V, Boussemart L, Gadue P, Nierhoff D, Koehler CI, Kubo A, et al. BMP-4 is required for hepatic specification of mouse embryonic stem cell-derived definitive endoderm. Nat Biotechnol. 2006; 24:1402-11. [PubMed: 17086172]

46. Yasunaga M, Tada S, Torikai-Nishikawa S, Nakano Y, Okada M, Jakt LM, et al. Induction and monitoring of definitive and visceral endoderm differentiation of mouse ES cells. Nat Biotechnol. 2005; 23:1542-50. [PubMed: 16311587]

47. Wang P, Rodriguez RT, Wang J, Ghodasara A, Kim SK. Targeting SOX17 in human embryonic stem cells creates unique strategies for isolating and analyzing developing endoderm. Cell Stem Cell. 2011; 8:335-46. [PubMed: 21362573]

48. Green MD, Chen A, Nostro MC, d'Souza SL, Schaniel C, Lemischka IR, et al. Generation of anterior foregut endoderm from human embryonic and induced pluripotent stem cells. Nat Biotechnol. 2011; 29:267-72. [PubMed: 21358635]

49. Sherwood RI, Jitianu C, Cleaver O, Shaywitz DA, Lamenzo JO, Chen AE, et al. Prospective isolation and global gene expression analysis of definitive and visceral endoderm. Dev Biol. 2007; 304:541-55. [PubMed: 17328885]

50. Yang L, Soonpaa MH, Adler ED, Roepke TK, Kattman SJ, Kennedy M, et al. Human cardiovascular progenitor cells develop from a KDR+ embryonic-stem-cell-derived population. Nature. 2008; 453:524-8. [PubMed: 18432194]

51. Ungrin MD, Clarke G, Yin T, Niebrugge S, Nostro MC, Sarangi F, et al. Rational bioprocess design for human pluripotent stem cell expansion and endoderm differentiation based on cellular dynamics. Biotechnol Bioeng. 2011

52. Lowe LA, Yamada S, Kuehn MR. Genetic dissection of nodal function in patterning the mouse embryo. Development. 2001; 128:1831-43. [PubMed: 11311163]

53. Lee MA, Heasman J, Whitman M. Timing of endogenous activin-like signals and regional specification of the Xenopus embryo. Development. 2001; 128:2939-52. [PubMed: 11532917]

54. Perea-Gomez A, Vella FD, Shawlot W, Oulad-Abdelghani M, Chazaud C, Meno C, et al. Nodal antagonists in the anterior visceral endoderm prevent the formation of multiple primitive streaks. Dev Cell. 2002; 3:745-56. [PubMed: 12431380]

55. Spence JR, Mayhew CN, Rankin SA, Kuhar MF, Vallance JE, Tolle K, et al. Directed differentiation of human pluripotent stem cells into intestinal tissue in vitro. Nature. 2011; 470:105-9. [PubMed: 21151107]

56. Kinder SJ, Tsang TE, Quinlan GA, Hadjantonakis AK, Nagy A, Tam PP. The orderly allocation of mesodermal cells to the extraembryonic structures and the anteroposterior axis during gastrulation of the mouse embryo. Development (Cambridge, England). 1999; 126:4691.

57. Kouskoff V, Lacaud G, Schwantz S, Fehling HJ, Keller G. Sequential development of hematopoietic and cardiac mesoderm during embryonic stem cell differentiation. Proceedings of the National Academy of Sciences of the United States of America. 2005; 102:13170. [PubMed: 16141334]

58. Dessimoz J, Opoka R, Kordich JJ, Grapin-Botton A, Wells JM. FGF signaling is necessary for establishing gut tube domains along the anterior-posterior axis in vivo. Mech Dev. 2006; 123:4255. [PubMed: 16326079]

59. McLin VA, Rankin SA, Zorn AM. Repression of Wnt/beta-catenin signaling in the anterior endoderm is essential for liver and pancreas development. Development. 2007; 134:2207-17. [PubMed: 17507400]

60. Ye F, Duvillie B, Scharfmann R. Fibroblast growth factors 7 and 10 are expressed in the human embryonic pancreatic mesenchyme and promote the proliferation of embryonic pancreatic epithelial cells. Diabetologia. 2005; 48:277-81. [PubMed: 15690149]

61. Apelqvist A, Li H, Sommer L, Beatus P, Anderson DJ, Honjo T, et al. Notch signalling controls pancreatic cell differentiation. Nature. 1999; 400:877-81. [PubMed: 10476967]

62. Bhushan A, Itoh N, Kato S, Thiery JP, Czernichow P, Bellusci S, et al. Fgf10 is essential for maintaining the proliferative capacity of epithelial progenitor cells during early pancreatic organogenesis. Development. 2001; 128:5109-17. [PubMed: 11748146] 
63. Hart A, Papadopoulou S, Edlund H. Fgf10 maintains notch activation, stimulates proliferation, and blocks differentiation of pancreatic epithelial cells. Dev Dyn. 2003; 228:185-93. [PubMed: 14517990]

64. Jensen J, Pedersen EE, Galante P, Hald J, Heller RS, Ishibashi M, et al. Control of endodermal endocrine development by Hes-1. Nat Genet. 2000; 24:36-44. [PubMed: 10615124]

65. Norgaard GA, Jensen JN, Jensen J. FGF10 signaling maintains the pancreatic progenitor cell state revealing a novel role of Notch in organ development. Dev Biol. 2003; 264:323-38. [PubMed: 14651921]

66. Kelly OG, Chan MY, Martinson LA, Kadoya K, Ostertag TM, Ross KG, et al. Cell-surface markers for the isolation of pancreatic cell types derived from human embryonic stem cells. Nat Biotechnol. 2011; 29:750-6. [PubMed: 21804561]

67. Spence JR, Lange AW, Lin SC, Kaestner KH, Lowy AM, Kim I, et al. Sox17 regulates organ lineage segregation of ventral foregut progenitor cells. Dev Cell. 2009; 17:62-74. [PubMed: 19619492]

68. Wandzioch E, Zaret KS. Dynamic signaling network for the specification of embryonic pancreas and liver progenitors. Science. 2009; 324:1707-10. [PubMed: 19556507]

69. Rossi JM, Dunn NR, Hogan BL, Zaret KS. Distinct mesodermal signals, including BMPs from the septum transversum mesenchyme, are required in combination for hepatogenesis from the endoderm. Genes Dev. 2001; 15:1998-2009. [PubMed: 11485993]

70. Bar-Nur O, Russ HA, Efrat S, Benvenisty N. Epigenetic memory and preferential lineage-specific differentiation in induced pluripotent stem cells derived from human pancreatic islet Beta cells. Cell Stem Cell. 2011; 9:17-23. [PubMed: 21726830]

71. Kim K, Doi A, Wen B, Ng K, Zhao R, Cahan P, et al. Epigenetic memory in induced pluripotent stem cells. Nature. 2010; 467:285-90. [PubMed: 20644535]

72. Osafune K, Caron L, Borowiak M, Martinez RJ, Fitz-Gerald CS, Sato Y, et al. Marked differences in differentiation propensity among human embryonic stem cell lines. Nat Biotechnol. 2008; 26:313-5. [PubMed: 18278034]

73. Polo JM, Liu S, Figueroa ME, Kulalert W, Eminli S, Tan KY, et al. Cell type of origin influences the molecular and functional properties of mouse induced pluripotent stem cells. Nat Biotechnol. 2010; 28:848-55. [PubMed: 20644536]

74. Kumar M, Jordan N, Melton D, Grapin-Botton A. Signals from lateral plate mesoderm instruct endoderm toward a pancreatic fate. Dev Biol. 2003; 259:109-22. [PubMed: 12812792]

75. Martin M, Gallego-Llamas J, Ribes V, Kedinger M, Niederreither K, Chambon P, et al. Dorsal pancreas agenesis in retinoic acid-deficient Raldh2 mutant mice. Dev Biol. 2005; 284:399-411. [PubMed: 16026781]

76. Molotkov A, Molotkova N, Duester G. Retinoic acid generated by Raldh2 in mesoderm is required for mouse dorsal endodermal pancreas development. Dev Dyn. 2005; 232:950-7. [PubMed: 15739227]

77. Stafford D, Prince VE. Retinoic acid signaling is required for a critical early step in zebrafish pancreatic development. Curr Biol. 2002; 12:1215-20. [PubMed: 12176331]

78. Hebrok M, Kim SK, Melton DA. Notochord repression of endodermal Sonic hedgehog permits pancreas development. Genes Dev. 1998; 12:1705-13. [PubMed: 9620856]

79. Apelqvist A, Ahlgren U, Edlund H. Sonic hedgehog directs specialised mesoderm differentiation in the intestine and pancreas. Curr Biol. 1997; 7:801-4. [PubMed: 9368764]

80. Chen S, Borowiak M, Fox JL, Maehr R, Osafune K, Davidow L, et al. A small molecule that directs differentiation of human ESCs into the pancreatic lineage. Nature chemical biology. 2009; 5:258-65.

81. Maehr R, Chen S, Snitow M, Ludwig T, Yagasaki L, Goland R, et al. Generation of pluripotent stem cells from patients with type 1 diabetes. Proc Natl Acad Sci U S A. 2009; 106:15768-73. [PubMed: 19720998]

82. Thatava T, Nelson TJ, Edukulla R, Sakuma T, Ohmine S, Tonne JM, et al. Indolactam V/GLP-1mediated differentiation of human iPS cells into glucose-responsive insulin-secreting progeny. Gene Ther. 2010; 18:283-93. [PubMed: 21048796] 
83. Gittes GK. Developmental biology of the pancreas: a comprehensive review. Dev Biol. 2009; 326:4-35. [PubMed: 19013144]

84. Lee JC, Smith SB, Watada H, Lin J, Scheel D, Wang J, et al. Regulation of the pancreatic proendocrine gene neurogenin3. Diabetes. 2001; 50:928-36. [PubMed: 11334435]

85. Murtaugh LC, Stanger BZ, Kwan KM, Melton DA. Notch signaling controls multiple steps of pancreatic differentiation. Proc Natl Acad Sci U S A. 2003; 100:14920-5. [PubMed: 14657333]

86. Bardeesy N, Cheng KH, Berger JH, Chu GC, Pahler J, Olson P, et al. Smad4 is dispensable for normal pancreas development yet critical in progression and tumor biology of pancreas cancer. Genes Dev. 2006; 20:3130-46. [PubMed: 17114584]

87. Basford CL, Prentice KJ, Hardy AB, Sarangi F, Micallef SJ, Li X, et al. The functional and molecular characterisation of human embryonic stem cell-derived insulin-positive cells compared with adult pancreatic beta cells. Diabetologia. 2011; 55:358-71. [PubMed: 22075915]

88. Jeon J, Correa-Medina M, Ricordi C, Edlund H, Diez JA. Endocrine cell clustering during human pancreas development. J Histochem Cytochem. 2009; 57:811-24. [PubMed: 19365093]

89. Riedel MJ, Asadi A, Wang R, Ao Z, Warnock GL, Kieffer TJ. Immunohistochemical characterisation of cells co-producing insulin and glucagon in the developing human pancreas. Diabetologia. 2011; 55:372-81. [PubMed: 22038519]

90. Collombat P, Xu X, Ravassard P, Sosa-Pineda B, Dussaud S, Billestrup N, et al. The ectopic expression of Pax 4 in the mouse pancreas converts progenitor cells into alpha and subsequently beta cells. Cell. 2009; 138:449-62. [PubMed: 19665969]

91. Chung CH, Hao E, Piran R, Keinan E, Levine F. Pancreatic beta-cell neogenesis by direct conversion from mature alpha-cells. Stem Cells. 2010; 28:1630-8. [PubMed: 20653050]

92. Thorel F, Nepote V, Avril I, Kohno K, Desgraz R, Chera S, et al. Conversion of adult pancreatic alpha-cells to beta-cells after extreme beta-cell loss. Nature. 2010; 464:1149-54. [PubMed: 20364121]

93. Chambers SM, Fasano CA, Papapetrou EP, Tomishima M, Sadelain M, Studer L. Highly efficient neural conversion of human ES and iPS cells by dual inhibition of SMAD signaling. Nat Biotechnol. 2009; 27:275-80. [PubMed: 19252484] 


\section{Highlights}

- We reviewed recent progress on the generation of beta cells from hPSCs.

- We discussed the signaling pathways required for hPSC commitment to the pancreatic lineages.

- We discussed the importance of reproducing first and secondary transition in vitro.

- We discussed the generation of poly-hormonal cells in vitro, their potential role in embryonic development and the possibility to transdifferentiate these cells to beta cells.

- We identified current challenges and suggested potential approaches to generate functional beta cell in vitro from hPSCs. 


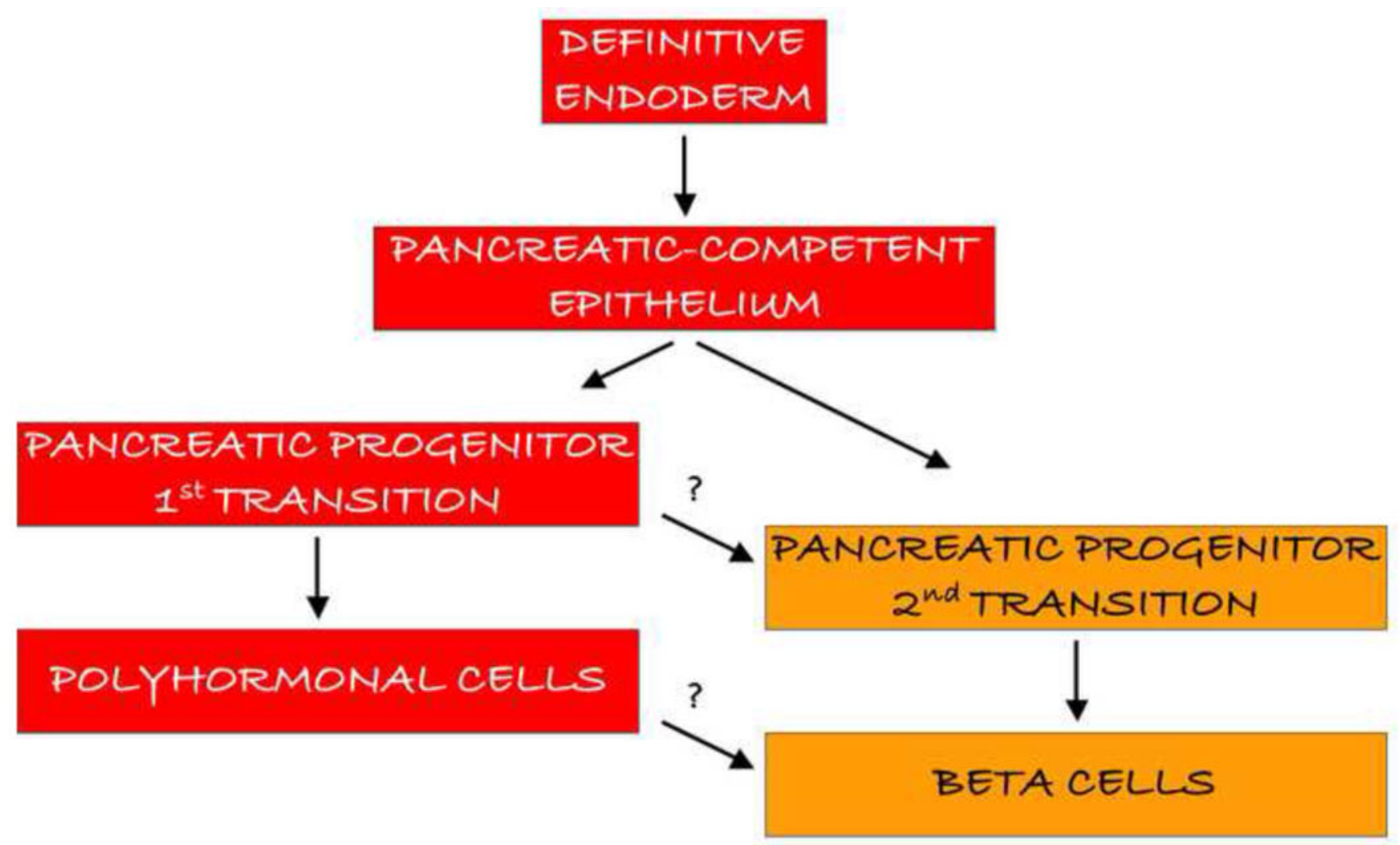

Figure 1. Schematic representation of the developmental steps leading to beta cells development Insulin-producing cells are generated in two distinct phases during embryonic development, known as the first and second transition. The cells produced during the first transition, are predominantly poly-hormonal and do not contribute to the adult islets of Langherans. During the second transition, adult beta cells arise from a multipotent progenitor that expresses pdx1, nkx6-1, sox9 and ptf1a. In the absence of nkx6.1 adult beta cells are not generated. Using hPSCs to model pancreatic development, we have recapitulated the steps leading to the formation of $1^{\text {st }}$ transition pancreatic progenitors (highlighted in red). Signaling pathways leading to the generation of the progenitors of the second transition and beta cells in vitro still remain to be elucidated (highlighted in orange). 


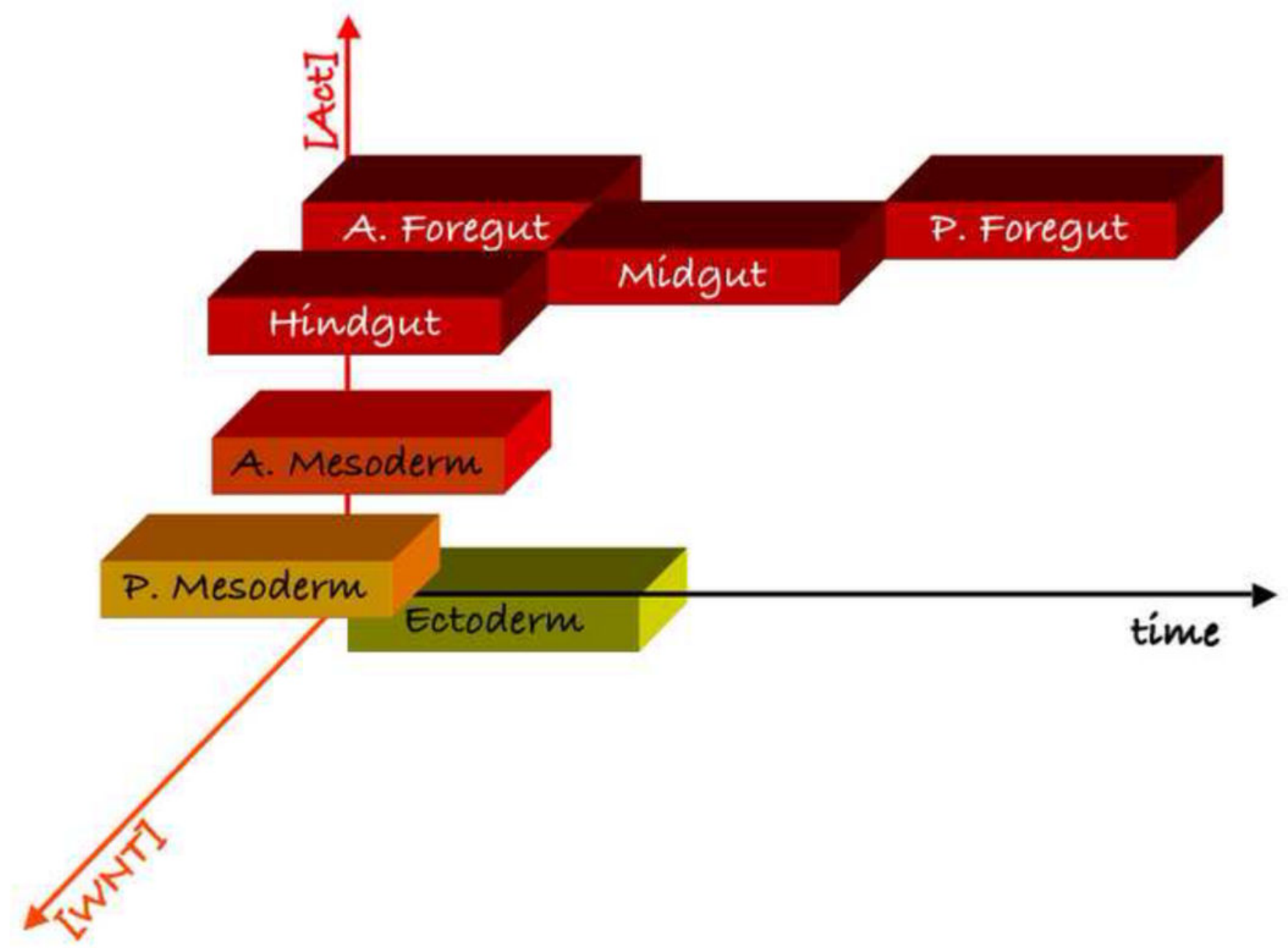

Figure 2. Three-dimensional representation of the signaling requirements for germ layer induction from hPSCs

Endoderm (red blocks) arises in the presence of high concentration of Activin A and low levels of canonical WNT signaling [42, 43]. Short exposure to Activin A and WNT (in the absence of BMP, not in the figure) will lead to the formation of the anterior foregut endoderm (A. Foregut) [48]. A longer period of Activin A signaling will induce posterior foregut endoderm (P. Foregut), whereas intermediate exposure together with increasing canonical WNT signaling will give rise to midgut and hindgut endoderm (Ogawa in preparation) [38, 55]. Lower levels of Activin A signaling will induce anterior (A. Mesoderm) and posterior mesoderm (P. Mesoderm) (orange and yellow blocks) [43]. Ectoderm is induced in the absence of Activin A, WNT (and BMP, not in the figure) (green block) [93]. 


\section{$D E \quad \rightarrow \quad P G \quad \rightarrow \quad 1^{\text {st } P P}$}

\section{PE}

NOTCH Inhíb.

\section{SHH Inhibition}

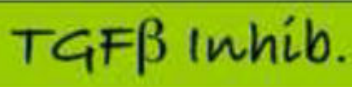

\section{BMP Inhibition}

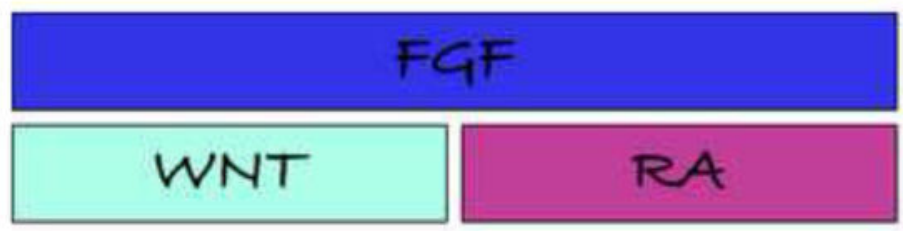

Forskolin

Figure 3. Schematic representation of the signaling pathways that regulate the development of first transition endocrine cells from hPSCs

Pancreatic lineage specification from hPSC-derived definitive endoderm requires stage specific inhibition of the BMP, SHH, TGF- $\beta$ and NOTCH pathways. BMP inhibition is required throughout the differentiation while FGF signaling and SHH inhibition are required during endoderm patterning (Definitive Endoderm, DE to Primitive Gut, PG) and pancreatic specification (PG to the Pancreatic Progenitor of the first transition $1^{\text {st }} \mathrm{PP}$ ). Canonical WNT is required to pattern definitive endoderm to a pancreatic-competent epithelium (DE to PG) and RA is important for pancreatic specification (PG to $1^{\text {st }} \mathrm{PP}$ ). Endocrine lineage commitment is achieved in the presence of BMP/TGF- $\beta / \mathrm{NOTCH}$ inhibition and forskolin treatment $\left(1^{\text {st }} \mathrm{PP}\right.$ to Pancreatic Endocrine, $\left.\mathrm{PE}\right)$. 


\section{Table 1}

Requirement for BMP inhibition prior to PDX1 induction is cell line-dependent

\begin{tabular}{|c|c|}
\hline Cell Line & BMP Inhibition at stage 2 \\
\hline H1 $[31,32,38,41]$ & $\mathrm{Y}$ \\
$\mathrm{N}^{*}[39]$ \\
\hline $\mathrm{H} 9[31,32,38,41]$ & $\mathrm{Y}$ \\
\hline H7 [32] & $\mathrm{Y}$ \\
\hline HES2 [38] & $\mathrm{N}$ \\
\hline HES3 [38] & $\mathrm{Y}$ \\
\hline $38-2$ IPS [38] & $\mathrm{N}$ \\
\hline VUB01, 02, 07, 14, 17 [36] & $\mathrm{Y}$ \\
\hline HSF6 [36] & $\mathrm{Y}$ \\
\hline Cyt25, 49 203 [28] & $\mathrm{N}$ \\
\hline BG02, BG01 [28] & $?$ \\
\hline
\end{tabular}

BMP inhibition is not required prior to PDX1 induction in this protocol 
Table 2

Specification of the pancreatic epithelium

\begin{tabular}{|c|c|c|}
\hline Contribution & $\begin{array}{c}\text { Stage 2 } \\
\text { Endoderm Patterning }\end{array}$ & $\begin{array}{c}\text { Stage } 3 \\
\text { PDX1 Induction }\end{array}$ \\
\hline & \multicolumn{2}{|l|}{ RA @ stage 3} \\
\hline D'Amour 2006 & FGF10+Cyclo 2-4days & RA+Cyclo+FGF10 2-4days \\
\hline Kroon 2008 & FGF7+ $2 \%$ FBS 4days & $\mathrm{RA}+\mathrm{NOG}+$ Cyclo 3days \\
\hline Rezania 2011 & FGF7+Cyclo 2days & $\mathrm{RA}+\mathrm{NOG}+\mathrm{Cyclo}+\mathrm{FGF} 7$ 4days \\
\hline Nostro 2011 & FGF10+Wnt +/- Dorsomorphin 3days & $\mathrm{RA}+\mathrm{NOG}+\mathrm{Cyclo}+\mathrm{FGF} 10$ 3days \\
\hline \multirow[t]{2}{*}{ Micallef 2011} & NOG 3 days & RA 3 days RA+GLP1+Nicotinamide 7 days \\
\hline & \multicolumn{2}{|l|}{ RA @ stage 2+3 } \\
\hline Cai 2007 & \multicolumn{2}{|l|}{ FGF7+RA 6days } \\
\hline Johannenson 2009 & \multicolumn{2}{|l|}{ FGF4+RA 7days } \\
\hline Zhang 2009 & FGF7+RA+NOG 4days & EGF 5days \\
\hline Mfopou 2010 & $\mathrm{RA}^{*}+\mathrm{NOG}+\mathrm{Cyclo}+\mathrm{FBS}^{* *}$ 8days Endogenous FGF signaling & FGF10+EX4+ Compound E 4days \\
\hline \multirow[t]{2}{*}{ Kunisada 2011} & \multicolumn{2}{|c|}{ RA+Dorsomorphin+SB 7days } \\
\hline & \multicolumn{2}{|l|}{ No RA } \\
\hline Jiang 2007 & FGF2, EGF, NOG 14 days & EGF NOG 7days \\
\hline Ameri 2009 & \multicolumn{2}{|l|}{ FGF2 6-8 days } \\
\hline Xu 2011 & \multicolumn{2}{|c|}{ MEF CM+FGF2 14 days } \\
\hline
\end{tabular}

* In some instances RA treatment was postponed by two days.

FBS was used for the first four days only. 